\title{
OP54
}

\section{A NEW METHOD FOR EVALUATING THE VISUAL ENVIRONMENT}

\author{
Hillevi Hemphälä et al.
}

DOI 10.25039/x46.2019.OP54

from

CIE x046:2019

\section{Proceedings}

of the

29th CIE SESSION

Washington D.C., USA, June 14 - 22, 2019

(DOI 10.25039/x46.2019)

The paper has been presented at the 29th CIE Session, Washington D.C., USA, June 14-22, 2019. It has not been peer-reviewed by CIE.

(C) CIE 2019

All rights reserved. Unless otherwise specified, no part of this publication may be reproduced or utilized in any form or by any means, electronic or mechanical, including photocopying and microfilm, without permission in writing from CIE Central Bureau at the address below. Any mention of organizations or products does not imply endorsement by the CIE.

This paper is made available open access for individual use. However, in all other cases all rights are reserved unless explicit permission is sought from and given by the CIE.

CIE Central Bureau

Babenbergerstrasse 9

A-1010 Vienna

Austria

Tel.: +4317143187

e-mail: ciecb@cie.co.at

www.cie.co.at 


\title{
A NEW METHOD FOR EVALUATING THE VISUAL ENVIRONMENT
}

\author{
Hillevi Hemphälä ${ }^{1}$, Helena Olivik ${ }^{1}$ \\ ${ }^{1}$ Division for Ergonomics and Aerosol Technologies, Design Sciences, Lund University, Lund, \\ SWEDEN \\ hillevi.hemphala@design.Ith.se
}

DOI $10.25039 / \times 46.2019 .0 P 54$

\begin{abstract}
VERAM, Visual Ergonomics Risk Assessment Method, is a valid, reliable, practical and easy to use risk assessment method for evaluating the visual environment. With this method, the risk factors in the visual environment is detected and interventions can be implemented to reduce the occurrence of symptoms related to poor visual ergonomics among workers in different type of work, not only computer work.

A visual environment that causes glare, have to high luminance ratio and/or give too low levels of illuminance can cause eyestrain and musculoskeletal strain for individuals at work. The visual ability and experience of visual blur is significant when the risk for glare is high or the illuminance is insufficient. To increase performance and occupational health, reduce sick leave, a good visual environment is required.
\end{abstract}

Keywords: Glare, luminance, eyestrain, musculoskeletal strain, vision, visual stimuli

\section{Introduction}

The visual environment can affect our wellbeing in many ways. Glare from luminaries or windows within the visual field can cause disability glare and/or discomfort glare (Anshel, 2007; Rosenfield, 2011). The visual environment must be designed to allow natural light coming in, but have the ability to prevent disturbing light (Osterhaus et al., 2015). Glare while performing tasks on the computer causes visual fatigue and can lead to strabismus measured by fixation disparity, i.e. decreased ability for the eyes to focus (Glimne et al., 2013). Visual and ocular symptoms are frequently reported problems associated with near work (Gowrisankaran et al., 2015; Hashemi et al., 2017; Mowatt et al., 2018; Zetterberg et al., 2016). Musculoskeletal problems in neck and shoulders are also reported in a high degree when performing visually demanding near work, such as computer work (Agrawal et al., 2017; Collins et al., 2015). Studies also show that there is a correlation between visually demanding work, i.e. straining the eye, and an increase in musculoskeletal strain (Helland et al., 2008; Hemphälä et al., 2011; Lie et al., 1987, Wiholm et al., 2007; Zetterberg et al., 2017). Insufficient visual ability can lead to increased workload and contribute to eyestrain and musculoskeletal disorders, which in turn can lead to sick leave. Although mostly recognized in computer work (Blehm et al., 2005; Dainoff et al., 2005), the impact of high visual demands on workers' wellbeing has been demonstrated in other types of occupations as well (Bogdanova et al, 2016; Hemphälä, 2014; Juslén et al., 2005; Lindegård et al., 2016).

Valid and reliable risk assessment methods are required in order to detect risks in the visual environment, and to evaluate workplace interventions. Preferably, they should cover all aspects of the work environment, such as workstation arrangement, task demands, and the worker's perceived visual comfort (Jackson et al., 1997; Long, 2014). Leccese et al. (2016) recommends that objective measurements of luminance should be performed at the workstation (e.g., the desk) as well as in the surroundings (e.g., the surrounding walls) to get a complete assessment of the lighting conditions. Further, they stressed the need to also consider the worker's perception of visual comfort in the assessment (Leccese et al., 2017).

Questionnaires for assessing visual fatigue and eyestrain associated with office work have been used before (Knave et al., 1985; Rajabi-Vardanjani et al., 2014; Segui et al, 2015). In Knave et al. (1985), an extensive set of questions about the frequency and intensity of eye discomfort, together with musculoskeletal symptoms, was distributed to office employees. The study 
showed associations between ratings of eye discomfort, musculoskeletal discomfort, and headache (Knave et al., 1985). Rajabi-Vardanjani et al. (2014) described the development of the 15-item Visual Fatigue Questionnaire for video display terminal (VDT) users, including questions about eyestrain, impaired vision, and symptoms from the eyes. They confirmed its validity and reliability relative to physiological measurements of fatigue (Rajabi-Vardanjani et al., 2014) Segui et al. (2015) designed and validated a Computer Vision Syndrome Questionnaire for assessing ocular and visual symptoms related to VDT use. The Ocular Surface Disease Index is a 12-item questionnaire concerning symptoms and function of the eyes. It has been shown to be a valid and reliable instrument for assessing dry eye syndrome (Schiffman et al., 2000; Özcura et al., 2007), and can be used for screening for symptoms among workers in any occupation.

To satisfy the need for a generic risk assessment tool with a holistic approach, a computerbased Visual Ergonomics Risk Assessment Method (VERAM) has been developed. VERAM can be used in a variety of work types. It contains subjective ratings by the worker as well as objective assessments and measurements of the work environment. Together, they form the basis for assessing risks associated with the visual environment. VERAM is a validated and reliable tool to use for risk assessments in the visual environment (Heiden et al., 2019; Zetterberg et al., 2019).

The aim of this paper is to present preliminary data from the gathered material regarding the risk assessments performed for illuminance and general risk for glare. These two factors are then compared to the some of the ratings in the subjective questionnaire such as eyestrain, headache, visual ability and musculoskeletal strain.

\section{Method}

The risk assessment method was developed in collaboration with researchers and practitioners in ergonomics, and tested by practitioners before being finalized. During 2015 and 2016, courses in visual ergonomics risk assessment were offered to practitioners from occupational health services, free of charge. Each course participant performed workplace evaluations using VERAM. The data gathered through this process is extensive and only part of it is analyzed in this article. The data from 48 trained evaluators, employees from occupational health departments, and 266 workplace evaluations, both computer and non-computer work. More articles will be published analyzing all of the gathered material.

VERAM contains 1) a questionnaire for the worker (e.g. eyestrain, headache, musculoskeletal discomfort), 2) an objective evaluation form for the evaluator (e.g., measuring luminance and illuminance; and rating glare, flicker, workstation arrangements, task demands), 3) a section of follow-up questions based on the worker's responses, and 4) a section for recommended changes, including an overall risk assessment with respect to daylight, lighting, illuminance, glare, flicker, workspace, work object and work postures, respectively. Each main factor (e.g. risk for glare, risk for flicker/temporal light artefacts, daylight, illuminance levels, work postures, work object) was divided into no risk (green), risk (yellow) and high risk (red). The final version was implemented electronically, to be used on computers or tablets.

\subsection{Subjective ratings - Questionnaire}

In the questionnaire the individuals' eyestrain, visual ability, and musculoskeletal pain are rated. The data presented in this paper are based on the following questions:

\section{Burning}

Itching

Gritty Feeling

Eye Pain

Light Sensitivity
Do you experience any burning sensation in your eyes during the past four weeks?

Do you experience any itching in your eyes during the past four weeks?

Do you experience any gritty feeling in your eyes during the past four weeks?

Do you experience any pain in your eyes during the past four weeks?

Do you experience any light sensitivity during the past four weeks? 


Redness
Teariness
Eye Fatigue
Eyestrain
Vision
Blurriness
Diplopia
Chang dist/near
Migraine
Headache
Work-related Headache
Neck Pain
Shoulder Pain
Back Pain
Arm Pain
Glare

Do you experience any redness in your eyes during the past four weeks?

Do you experience any teariness the past four weeks?

Do you experience any eye fatigue during the past four weeks?

Sum of all rated eyestrain/asthenopia above.

The visual ability during the past four weeks

Any visual blur during the past four weeks

Any diplopia during the last past four weeks

Any problems changing your vision from near to distance or opposite

Any migraine during the past four weeks

Any headache during the past four weeks

Do you think the headache reported is work related

Any Neck pain during the past four weeks

Any shoulder pain during the past four weeks

Any back pain during the past four weeks

Any arm pain during the past four weeks

Are you experiencing any light sources that are to strong/glary at your work place

For more information regarding the outlay of the study see Zetterberg et al., 2019 and Heiden et al., 2019.

\subsection{Objective assessments}

The luminance and illuminance at each work place is measured. The main assessed risks in the visual environment presented in this paper are based on following factors:
Illuminance
Is the recommendations for this type of work place regarding the lux levels fulfilled? (according to the European lighting standard SS-EN 12464-1) (red - not fulfilled, high risk; yellow - partially fulfilled, risk; green - fulfilled, low/no risk)
General Glare
If the luminance ratio is:
$>1: 20$ it is rated as red: high risk
$>1: 5$ and $<1: 20$ it is rated as yellow: risk
$<1: 5$ is rated as green: low risk
Is there any risk present for direct glare from the luminaires?
(green/yellow/red)
Overall risk for glare at this work place? (green/yellow/red)

For more information regarding the outlay of the study see Zetterberg et al., 2019 and Heiden et al., 2019.

\subsection{Statistical analysis}

The results presented here are preliminary results. The statistical analysis was performed with non-parametric tests, Kruskal Wallis Test using IBM SPSS Statistics program, version 25 (2017). The material is not adjusted for mass significance.

The study was conducted in accordance with the Declaration of Helsinki, and approved by the Regional Ethical Review Board in Lund, Sweden (No. 2015/2).

\section{Result}

The results showed that the evaluators noticed a high risk for glare (red) in $22 \%$ of the workplaces and $40 \%$ of the work places had a risk for glare (yellow). The individual rating in the questionnaire of the presence of glare (too strong light sources) stated that $10 \%$ experienced glare often or always and $27 \%$ experienced glare sometimes. (See Table 1) 
Table 1 - Objective and subjective risk for glare Percentage of workplaces rated with glare.

Green is no/very low risk; yellow is risk present; red is high risk present. $(n=254)$

\begin{tabular}{|l|l|l|}
\hline & Subjective risk for Glare (\%) & Objective risk for glare (\%) \\
\hline No glare/green & 0.67 & 0.38 \\
\hline sometimes glare/yellow & 0.27 & 0.40 \\
\hline Often or always glare/red & 0.10 & 0.22 \\
\hline
\end{tabular}

Individuals that reported eyestrain such as eye pain, light sensitivity, dryness, and eye fatigue had significantly higher ratings for objective risk for glare and illuminance. (See Table 2) For the objective risk for illuminance more eyestrain symptoms were also significant.

Table 2 - p-values

for subjective ratings of eyestrain, headache, visual ability, and musculoskeletal strain from the questionnaire compared to the objective assessed risk from a trained evaluator for illuminance and glare, etc. $(n=252)\left({ }^{*}=\right.$ statistical significance of 0.05 or better)

\begin{tabular}{|l|r|r|}
\hline & Illuminance & \multicolumn{1}{|c|}{ General Glare } \\
\hline Burning & $0.003^{*}$ & 0.106 \\
\hline Itching & $0.010^{*}$ & 0.135 \\
\hline Gritty feeling & $0.016^{*}$ & 0.189 \\
\hline Eye pain & $0.001^{*}$ & $0.005^{*}$ \\
\hline Light sensitivity & $0.000^{*}$ & $0.000^{*}$ \\
\hline Redness & $0.010^{*}$ & 0.229 \\
\hline Teariness & $0.001^{*}$ & 0.357 \\
\hline Dryness & $0.001^{*}$ & $0.006^{*}$ \\
\hline Eye fatigue & $0.000^{*}$ & $0.000^{*}$ \\
\hline Eyestrain All & $0.000^{*}$ & $0.002^{*}$ \\
\hline Vision & 0.215 & $0.033^{*}$ \\
\hline Blurriness & 0.241 & $0.025^{*}$ \\
\hline Diplopia & 0.099 & 0.936 \\
\hline Change dist/near & 0.208 & 0.404 \\
\hline Migraine & 0.211 & 0.898 \\
\hline Headache & 0.669 & 0.574 \\
\hline Work-related Headache & $0.006^{*}$ & 0.378 \\
\hline Neck Pain & 0.062 & $0.001^{*}$ \\
\hline Shoulder Pain & $0.017^{*}$ & $0.011^{*}$ \\
\hline Back Pain & $0.000^{*}$ & $0.005^{*}$ \\
\hline Arm Pain & 0.212 & 0.085 \\
\hline
\end{tabular}

Individuals that stated problems with their visual ability had a significantly higher rating for the objective risk for glare $(p=0.33)$. If they reported any blurriness of their vision the objective risk for glare had a higher risk $(p=0.025)$. No significance was found for diplopia or focus changes (changes from near to distance or opposite).

No significance was found regarding risk for glare or illuminance for either migraine or headache. But if the headache was rated as work-related it showed a significance for the risk for illuminance $(p=0.006)$.

The rated neck pain had a significance to objective risk for glare $(p=0.001)$ but no significance towards risk of illuminance. The rated shoulder pain had a significance to both risk of illuminance $(p=0.017)$ and risk for glare $(p=0.011)$. Back pain also had a significance to both risk of illuminance $(p=0.000)$ and risk of glare $(p=0.005)$. No significance was found regarding arm pain and the risk of illuminance or glare. 


\section{Discussion}

The results showed that the evaluators noticed more risks than the individual worker did. According to the objective evaluation glare was present at $62 \%$ of the workplaces ( $40 \%$ yellow and $22 \%$ red). While the individuals rated the presence of glare (too strong luminaires) at $34 \%$ (24\% reported glare sometimes and $10 \%$ glare often/always). This shows that the ability to evaluate the risk for glare without any education is rather low. Most individuals do not have the frame of reference for what a good visual environment is, and do not question the lighting more than if the light is turned on or not. When being educated in the factors involved in a good visual environment the ability to question if the lighting or visual environment is good or not increases. This knowledge can improve the visual environment and decrease the amount of strain and improve performance. .

When the visual environment is rated yellow or red the risk for different types of eyestrain increase. Especially when the illuminance is to low or when there is glare present. The eyestrain increases when you have to strain your eyes in order to see more clearly.

When you strain your eyes you also have a higher musculoskeletal load on especially the neck and shoulder region.

Reports of blurriness and strained visual ability are higher when the visual environment is rated as red or yellow. The visual environment affects our visual ability, to increase our performance it is important to have an environment that is rated as green, as a good visual environment.

The presence of headache could not be explained by the visual environment, but when it was rated as work related there were a direct connection to the visual environment. If the headache is located around the eyes and temples, and develop during the day it is usually caused by vision related issues. It could be for example wrong power in spectacles or a visual environment rated as red or yellow.

Neck, shoulder and back pain increases if the visual environment (i.e. risk of glare and illuminance) is rated as yellow or red. This indicates a correlation between straining your eyes to enable vision and an increase in musculoskeletal load, also shown in studies (Zetterberg et al., 2017; Hemphälä et al., 2012). So a wrongly placed luminaire that causes glare or to low illuminance can lead to lower performance levels or even sick leave due to pain in the neck- or shoulder regions.

When the analysis of all of the gathered material is performed the results might be slightly different than presented here, even though these results are based on many work place evaluations. More articles will be published covering all of the gathered material.

\section{Conclusions}

To increase occupational health and reducing sick leave, a good visual environment is required. This includes sufficient illuminance, a good luminance ratio, no glare from luminaires or windows, and a good visibility of the task. The risk for glare is rated higher when a trained evaluator is rating it. Education in risk analysis of the visual environment is essential for many different occupations such as lighting designers, ergonomists, working life inspectors, and optometrists, to ensure a better understanding of the visual ergonomics impact on wellbeing.

\section{Acknowledgements}

We wish to thank Per Nylén (Swedish Working Life Authority), Per Lindberg, Marina Heiden and Camilla Zetterberg (Centre for Musculoskeletal Research, University of Gävle, Sweden) for the collaboration regarding VERAM. We also wish to thank the reference group participating in the development of VERAM. The group consisted of the following members from Sweden (S), Norway (N) and Denmark (DK):

Allan Toomingas, MD PhD (S); Ann-Kristin Nyström, Physiotherapist (S); Carl Lind, PhD (S); Catarina Nordander, MD PhD (S); Eja Pedersen, PhD (S); Eva Jangdin, Physiotherapist (S); Göran M Hägg, Professor Emeritus (S); Hanne-Mari Schiötz Thorud, Physiotherapist PhD (N); Hans Richter, Professor (S); Inger Arvidsson, Physiotherapist PhD, (S); Knut-Inge Fostervold, 
Professor (N); Magne Helland, Optometrist PhD (N); Peder Wibom, Lighting Designer (S); Per Odenrick, Professor (S); Peter Palm, Physiotherapist PhD (S); Teresia Nyman, Physiotherapist PhD (S); Thorbjörn Laike, Professor (S); Werner Osterhaus, Professor (DK).

Funding: This work was supported by AFA Insurance, Sweden [grant number 130166], Lund University and the University of Gävle.

\section{References}

Agrawal, P.R., Maiya, A.G., Kamath, V., Kamath, A., 2017. Work related musculoskeletal disorders among medical laboratory professionals: a narrative review. Int J Res Med Sci. 2, $1262-1266$.

Anshel, J.R., 2007. Visual Ergonomics in the Workplace. Cont. Educ. 55, 414-420.

Blehm, C., Vishnu, S., Khattak, A., Mitra, S., Yee, R.W., 2005. Computer vision syndrome: a review. Surv Ophthalmol. 50, 253-262.

Bogdanova, R., Boulanger, P., Zheng, B., 2016. Depth Perception of Surgeons in Minimally Invasive Surgery. Surg. Innov. 23, 515-524.

Collins, J.D., O'Sullivan, L.W., 2015. Musculoskeletal disorder prevalence and psychosocial risk exposures by age and gender in a cohort of office based employees in two academic institutions. Int J Ind Ergon. 46, 85-97.

Dainoff, M.J., Aaras, A., Horgen, G., Konarska, M., Larsen, S., Thoresen, M., Cohen, B.G., 2005. The effect of an ergonomic intervention on musculoskeletal, psychosocial and visual strain of VDT entry work: organization and methodology of the international study. Int. J. Occup. Saf. Ergon. 11, 9-23.

Glimne, S., Öqvist Seimyr, G., Ygge, J., Nylén, P., Brautaset, R.L., 2013, Measuring glare induced visual fatigue by fixation disparity variation, Work, 45, 431-437.

Gowrisankaran, S., Sheedy, J.E., 2015. Computer vision syndrome: A review. Work. 52, 303314.

Hashemi, H., Khabazkhoob, M., Forouzesh, S., Nabovati, P., Yekta, A.A., Ostadimoghaddam, $\mathrm{H} ., 2017$. The prevalence of asthenopia and its Determinants among schoolchildren. $J$ Compr Ped. 8.

Heiden, M., Zetterberg, C., Lindberg, P., Nylén, P., Hemphälä, H., 2019, Validity of a computerbased risk assessment method for visual ergonomics, I.J. Industrial Ergonomics, Submitted for publication

Helland, M., Horgen, G., Kvikstad, T.M., Garthus, T., Bruenech, J.R., Aarås, A., 2008. Musculoskeletal, visual and psychosocial stress in VDU operators after moving to an ergonomically designed office landscape. Appl Ergon. 39, 284-295.

Hemphälä, H., Eklund, J., 2011. A visual ergonomics intervention in mail sorting facilities: Effects on eyes, muscles and productivity. Appl Ergon. 43, 217-229.

Hemphälä, H., 2014. How visual ergonomics interventions influence health and performance with an emphasis on non-computer work tasks. Faculty of Engineering, Lund University, Lund, Sweden.

Jackson, A.J., Barnett, E.S., Stevens, A.B., McClure, M., Patterson, C., McReynolds, M.J., 1997. Vision screening, eye examination and risk assessment of display screen users in a large regional teaching hospital. Ophthal. Physiol. Opt. 17, 187-195.

Juslen, H., Tenner, A., 2005. Mechanisms involved in enhancing human performance by changing the lighting in the industrial workplace. Int J Ind Ergonom. 35, 843-855. 
Knave, B.G., Wibom, R.I., Voss, M., Hedström, L.D., Bergqvist, U.O., 1985. Work with video display terminals among office employees. I. Subjective symptoms and discomfort. Scand J Work Environ Health. 11, 457-466.

Leccese, F., Salvadori, G., Rocca, M., 2016. Visual ergonomics of video-display-terminal workstations: field measurements of luminance for various display settings. Displays. 42, 9-18.

Leccese, F., Salvadori, G., Montagnani, C., Ciconi, A., Rocca, M., 2017. Lighting assessment of ergonomic workstation for radio diagnostic reporting. Int. J. Indust. Ergon. 57, 42-54.

Lie, I., Watten, R.G., 1987. Oculomotor factors in the aetiology of occupational cervicobrachial diseases (OCD). Eur J Appl Physiol Occup Physiol. 56, 151-156.

Lindegård, A., Nordander, C., Jacobsson, H., Arvidsson, I., 2016. Opting to wear prismatic spectacles was associated with reduced neck pain in dental personnel: a longitudinal cohort study. BMC Musculoskelet. Disord. 17, 347.

Long, J., 2014. What is Visual Ergonomics? Work. 47, 287-289.

Osterhaus, W., Hemphälä, H., Nylén, P., 2015. Ligting at Computer Workstations, Work, 52, 315-328.

Mowatt, L., Gordon, C., Santosh, A.B.R., Jones, T., 2018. Computer vision syndrome and ergonomic practices among undergraduate university students. Int J Clin Pract. 72, e13035.

Rajabi-Vardanjani, H., Habibi, E., Pourabdian, S., Dehghan, H., Maracy, M.R., 2014. Designing and validation a visual fatigue questionnaire for video display terminals operators. Int. J. Prev. Med. 5, 841-848.

Rosenfield, M., 2011. Computer vision syndrome: a review of ocular causes and potential treatments. Ophthal. Physiol. Opt. 31, 502-515.

Schiffman, R.M., Christianson, M.D., Jacobsen, G., Hirsch, J.D., Reis, B.L., 2000. Reliability and validity of the Ocular Surface Disease Index. Arch. Ophthalmol. 118, 615-621.

Segui, M.D., Cabrero-Garcia, J., Crespo, A., Verdu, J., Ronda, E., 2015. A reliable and valid questionnaire was developed to measure computer vision syndrome at the workplace. $J$ Clin Epidemiol. 68, 662-673.

Wiholm, C., Richter, H., Mathiassen, S.E., Toomingas, A., 2007. Associations between eyestrain and neck-shoulder symptoms among callcenter operators. Scand J Work Environ Health. 33, 54-59.

Zetterberg, C., 2016. The impact of visually demanding near work on neck/shoulder discomfort and trapezius muscle activity: Laboratory studies. Faculty of Medicine, Uppsala University, Uppsala, Sweden.

Zetterberg, C., Forsman, M., Richter, H.O., 2017. Neck/shoulder discomfort due to visually demanding experimental near work is influenced by previous neck pain, task duration, astigmatism, internal eye discomfort and accommodation. PLoS One. 12, e0182439.

Zetterberg, C., Heiden, M., Lindberg, P., Nylén, P., Hemphälä, H., 2019, Reliability of a new risk assessment method for visual ergonomics, I.J. Industrial Ergonomics, Accepted for publication

Özcura, F., Aydin, S., Helvaci, M.R., 2007. Ocular surface disease index for the diagnosis of dry eye syndrome. Ocul. Immunol. Inflamm. 15, 389-393. 